\section{Andamios Revista de Investigación Social}

\begin{abstract}
A
\end{abstract}
Andamios. Revista de Investigación

Social

ISSN: 1870-0063

revistaandamios@uacm.edu.mx

Universidad Autónoma de la Ciudad de

México

México

Oceja Limón, Sandra

La novela de guerrilla en México y el arte de las buenas pasadas

Andamios. Revista de Investigación Social, vol. 8, núm. 15, enero-abril, 2011, pp. 81-110

Universidad Autónoma de la Ciudad de México

Distrito Federal, México

Disponible en: http://www.redalyc.org/articulo.oa?id=62819892005

- Cómo citar el artículo

- Número completo

- Más información del artículo

- Página de la revista en redalyc.org

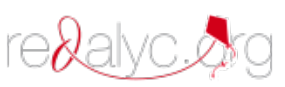

Sistema de Información Científica

Red de Revistas Científicas de América Latina, el Caribe, España y Portugal

Proyecto académico sin fines de lucro, desarrollado bajo la iniciativa de acceso abierto 


\title{
La novela de GuerRilla en México \\ Y EL ARTE DE LAS BUENAS PASADAS
}

Sandra O ceja Limón*

\begin{abstract}
ResUmen: Este artículo aborda sociológicamentela publicación de narrativas de ficción que tematizan las guerrillas urbanas de la década de los setenta en el México del siglo Xx. El propósito principal es demostrar cómo estas narrativas comprometen la lógica silente impuesta por los discursos dominantes en relación con ese periodo y se incorporan en el presente como símbolos que forman vacíos históricos y los transforman en espacios legibles, pues desempeñan, durante su lectura, un papel enunciador y movilizador de las representaciones sociales sobre las guerrillas urbanas. Propongo con esto quela literatura de ficción constituye, bajo una lógica que escapa a la racionalidad política y científica, un poder que penetra en el ánimo del lector y en el espacio y el tiempo histórico.

Palabras Clave: Insinuar (insinuer), polifonía, cronotopo, estrategia, táctica.
\end{abstract}

La lucha de un artista por una imagen definida y estable de su personajees [... ] una lucha consigo mismo.

M. M. BAJTIN, Estética de la creación verbal

\footnotetext{
*Licenciada en Sociología, Universidad Autónoma Metropolitana-Xochimilco. Profesora Investigadora de tiempo completo de la Universidad Autónoma de la Ciudad de México. Correo electrónico: sandra.oceja@gmail.com
} 
Preámbulo

El levantamiento armado del Ejército Zapatista de Liberación Nacional (EZLN) en 1994, en San Cristóbal de las Casas, Chiapas, México, constituye una fecha clave para las guerrillas de las décadas de los sesenta y setenta del M éxico del siglo Xx. Fue entonces que en la comunicación periodística y académica se comenzaron a debatir y a investigar (de manera consistente) las implicaciones de estos movimientos para los procesos democratizadores del Estado mexicano, pues hasta entonces las guerrillas mexicanas habían sido encubiertas por la omisión, la censura y la estigmatización en los discursos dominantes. Incluso, dicha recuperación académica y periodística hizo visibles a otros sectores de la sociedad. ${ }^{1}$

El resultado de lo anterior se concreta en una lenta pero creciente recuperación de información y testimonios, en el acceso a los escasos registros gubernamentales y en la conformación de líneas de investigación académica, con el propósito de reconstruir histórica y sociológicamente este periodo conocido como guerra sucia. ${ }^{2}$

En contraste con tal proceso de recuperación de información y la existencia en el presente de una lucha por la apropiación de un lugar

\footnotetext{
${ }^{1}$ Me refiero a ex guerrilleros, periodistas, familiares y amigos de los sobrevivientes 0 desaparecidos que desde el 2 de octubre de 1968 y la década de los setenta han luchado para lograr la presentación física de los desaparecidos, así como para tipificar jurídicamente las prácticas de tortura y asesinato emprendidas por los aparatos coercitivos del Estado.

${ }^{2}$ En materia de derecho internacional el término "guerra sucia" se aplica cuando los ejércitos se olvidan de la Convención de Ginebra, la cual exige que los contendientes respeten las reglas de rendición o capitulación, así como la calidad de los prisioneros de guerra. En cambio, este concepto se utiliza en nuestro país para caracterizar el periodo de mayor represión física y psicológica por parte del Estado mexicano para someter a la oposición, principalmente aquella que encabezaron los grupos armados durantela década de los setenta. En este sentido cabe señalar que fueron "los periodistas nacionales quienes a partir de la década de los ochenta retomaron el concepto del lenguaje de uso común en el cono sur, donde éste era empleado como indicativo del terror de las dictaduras militares, para denunciar situaciones irregulares de intervención del ejército contra las organizaciones guerrilleras y la población civil" (Cedillo, 2008: 76). El término guerra sucia se ha generalizado entre académicos, organizaciones civiles, sobrevivientes de dicho periodo y medios de comunicación de masas, así como en la sociedad en general, por lo que he decidido respetar esta convención.
} 
histórico, político y académico, nuestras guerrillas y la guerra sucia han sido continuamente (re)creadas desde la década de los setenta en un espacio al que no interesa la comprobación histórica: la literatura de ficción. En este sentido, los movimientos armados han sido tema central en una significativa cantidad de novelas, cuentos o relatos. Algunos de estos textos incluso fueron cread os bajo contextos históricos o coyunturas políticas que, en algunos casos, han sido adversas: desde los primeros años de la década de los setenta y hasta la fecha se han publicado aproximadamente 25 obras de ficción (novela, cuento y relato) en torno a los movimientos guerrilleros urbanos en el México de los setenta. ${ }^{3}$

La notoria producción literaria que se articula en torno a las guerrillas de nuestro país y el periodo de la guerra sucia, hace patente un fenómeno dentro de la narrativa mexicana en el seno de este mismo periodo histórico. Asimismo, considero que la existencia de una cantidad importante de estas novelas implica (intencionalmente o no) un distanciamiento de los autores frente a la posición que la historia oficial ocupa en la cultura de nuestro país.

Por lo tanto, me propongo en este artículo abordar sociológicamente las narrativas de ficción que dan cuenta específicamente de la existencia de las guerrillas urbanas de la década de los setenta y la llamada guerra sucia en el México del siglo Xx. En este sentido parto de dos premisas: en primer lugar sostengo que la ficción ha sido un medio por el cual dicho pasado se transforma en un presente significativo mediante la lectura de las realidades textuales que (re)crean lo no dicho en los discursos sociales dominantes y en la escritura de la historia. La segunda premisa me lleva a considerar que los vacíos históricos en los discursos dominantes no son autotélicos, sino que es condición sine qua non que otros discursos se confronten con tales discursos y cuestionen la visión oficial de la historia para evidenciar la omisión o el silencio en torno a otras memorias colectivas.

En efecto, los vacíos históricos sólo se crean y evidencian en el momento en que otras memorias entran en disputa con los referentes

\footnotetext{
${ }^{3} \mathrm{Al}$ final de este artículo se enlistan y especifican las referencias bibliográficas de esos textos. Cabe señalar aquí que ese listado no es exhaustivo.
} 
históricos que emanan de los estados democráticos modernos. Esta disputa representa políticamente una lucha por el reconocimiento y enunciación de dichas memorias en la reconstrucción histórica. Por esta razón pienso que los textos de ficción que tematizan las guerrillas urbanas de los setenta (algunos de ellos escritos por ex guerrilleros), entran también en conflicto; que si bien es cierto que las narrativas de ficción no se introducen como información histórica o periodística, ni como meros testimonios en las realidades creadas por los autores, lo que sí resulta es que se incorporan en el presente como símbolos de un pasado silenciado en la historia: estos textos desempeñan un papel enunciador y movilizador de las representaciones sociales sobre dicha época durante su lectura. Este es el punto de partida del presente artículo, el cual tiene como objetivo principal demostrar que la producción estética en torno a las guerrillas del siglo pasado insinúa (insinuer $)^{4}$ un poder que tiene la capacidad de producir vacíos en la historia y transformarlos en espacios legibles al incorporar la experiencia y la palabra hablada en los procesos de textualización.

Se puede decir entonces que las guerrillas y la guerra sucia, al ser recreadas por el lector, se traducen en espacios y tiempos simbólicos que se introducen en el ánimo, espacio y tiempo histórico/biográfico de éste. Durante su lectura la evocación de esas realidades textuales compromete los discursos sociales dominantes que dotan de sentido en el presente a los movimientos armados del pasado. Tales realidades textuales se transforman en referentes espacio-temporales que, al ser habitados/apropiados simbólicamente por el lector, (re)significan al mismo tiempo los discursos dominantes que circulan en la realidad social, de ahí también que las obras escritas se introducen físicamente en el espacio social e histórico.

\footnotetext{
${ }^{4}$ De acuerdo con Alejandro Pescador, traductor de Michel de Certeau (2000), este historiador utiliza el verbo insinuer en los dos sentidos que tiene en los usos del francés: “aparte del sentido de 'hacer penetrar en el ánimo', insinuer significa 'introducir' algo físico", (en deCerteau, 2000: XXIII).
} 
Antes de entrar en materia, es necesario establecer el carácter sociológico que la literatura de ficción tiene. Edward Said afirmó que "todos los textos tienen vínculos con el mundo y con sus circunstancias de acuerdo a unas condiciones que, por supuesto, varían de un género a otro y de un período histórico a otro" (Said, 2002: 48). Como acertadamente señala Mijail Bajtin (2003), toda obra contiene sus propios problemas históricos, ya que todo problema literario no se puede reducir meramente a sus aspectos formales. Por el contrario, implica forzosamente la orientación desde el punto de vista histórico para entender cualquier producción textual (Bajtin, 2003: 191). Cada obra contiene diversidad de proyecciones de carácter social que el autor (re)crea durante el proceso de producción (mientras está creando). De aquí que insista en "que toda obra literaria tiene internamente, inmanentemente, un carácter sociológico. En ella se cruzan las fuerzas sociales vivas, y cada elemento de su forma está impregnado de valoraciones sociales vivas" (2003: 191). Por ello, la peculiar configuración que representa cada una de las novelas de guerrilla "no puede ser separada de los análisis sociohistóricos, pero tampoco puede ser disuelta en los mismos" (Bajtin 2001a: 59-60). En otras palabras, la obra artística es un objeto cultural, la cual, además, debe entenderse como una unidad autónoma de su autor.

En efecto, una obra literaria es un objeto cultural pues concreta las representaciones sociales o formas interiorizadas de la cultura de las que su creador es portador: cuando hablamos de la obra estética como un producto cultural nos estamos refiriendo a las "formas objetivadas de la cultura" (Giménez, 2007: 45), las cuales expresan "la organización social de significados", esto es, la cultura interiorizada "por los sujetos en forma de esquemas o de representaciones compartidas, y objetivados en formas simbólicas, todo ello en contextos históricamente específicos y socialmente estructurados" (Giménez, 2007: 49). Dicho de otro modo:

Se trata de la distinción entre formas interiorizadas y formas objetivadas de la cultura. 0 en palabras de Bourdieu (1985: 
91), entre "formas simbólicas" y estructuras mentales interiorizadas, por un lado, y símbolos objetivados bajo formas de prácticas rituales y de objetos cotidianos, religiosos, artísticos, etcétera, por otro. En efecto, la concepción semiótica de la cultura nos obliga a vincular los modelos simbólicos a los actores que los incorporan subjetivamente ("modelos de") y lo expresan en sus prácticas ("modelos para") (Giménez, 2007: 44). ${ }^{5}$

En síntesis, me refiero a las determinaciones culturales de las que cada autor es portador, pues éste no suspende los esquemas interiorizados respecto al mundo. Finalmente, son dichos esquemas o representaciones la materia prima de la que se vale para crear su realidad estética: cada realidad representada estéticamente remite a los referentes existenciales (histórico/biográfico) del autor. Justamente, la palabra hablada al ser incorporada en los procesos de escritura permite rastrear, ya sea de manera diacrónica o sincrónica, los referentes culturales del autor; cualidades pendientes para futuras investigaciones.

Así pues, tales determinaciones (tomadas aquí como elementos de exterioridad) de una obra literaria son las representaciones que el autor tiene respecto a los temas tratados en su texto y a la información que éste tenga. "Los aspectos que se deben considerar son el estilo, las figuras del discurso, las escenas, los recursos narrativos y las circunstancias históricas y sociales" (Said, 2002: 45).

Ahora bien, sin detenerse en este debate, se encuentran dentro de los estudios literarios y la crítica literaria, distintas perspectivas en relación con la importancia del escritor/autor y su obra. En el presente caso, es necesario tomar al autor como un aspecto relevante que entra

\footnotetext{
${ }^{5}$ De acuerdo con Giménez , las representaciones sociales, son "formas interiorizadas de la cultura, [... ] permiten detectar esquemas subjetivos de percepción, de valoración y de acción que son la definición misma del habitus bourdieusiano" (Giménez, 2007: 49). "Las representaciones sociales son sistemas cognitivos contextualizados que responden a una doble lógica: la cognitiva y la social" (Giménez, 2007: 47). Cabe señalar que la homologación con Bourdieu elaborada por Giménez es útil para los propósitos de este artículo, como se verá más adel ante.
} 
en juego para comprometer la estructura de la novela, ya que "cumple el papel de enunciador dentro de la ficción" (Beristáin, 2003a, 70). En otras palabras: "no se puede [...] deslindar al autor, sigue siendo esencial, porque él está sobredeterminado por su contexto, por su marco histórico-cultural y, a través de él, también está sobredeterminada toda su obra." (Beristáin, 2003a, 70).

Lo anterior no significa que cada autor sea capaz de construir todos los discursos de una sociedad. Por el contrario, partimos del principio de que "en nuestras complejas sociedades modernas, ningún individuo se estructura en relación directa con toda la sociedad. La sociedad es una totalidad sumamente compleja y 'segmentada'". (Saltalamacchia, 1992: 159). Por ello, la organización y estructuración de los individuos son resultado de "alguna específica combinación de esos segmentos" (1992: 159). Así pues, el autor representa "un lugar de 'anudamiento' de un conjunto determinado de relaciones sociales. [...] por ende, representativo de ese particular nudo en el entretejido social" (1992: 296), y, al mismo tiempo, es portador de las representaciones circulantes respecto a otros individuos, clases, estratos, etcétera.

Por otro lado, el texto narrativo es un mensaje creado y organizado por el emisor (autor) con base en uno o varios códigos, el cual es transmitido por medio de un canal, en este caso, el texto escrito y dirigido a un destinatario: el lector. Durante la elaboración de la novela, los elementos que circulan en el interior del texto son creados por el autor para establecer los elementos extratextuales, es decir, cualquier referente biográfico, histórico, cultural, religioso, filosófico, etcétera. Esto permite al lector la exploración y exégesis del texto/mensaje como un sistema de comunicación.

De la misma manera, el autor es portador de las referencias culturales (re)elaboradas y puestas en discurso (al momento de la escritura) en el texto de ficción. Por ello, es el mismo autor quien delimita el espacio social que atraviesa a la obra. Así, cada personaje representa también una posición social que estructura la realidad textual simbolizada; un espacio social configurado desde otros discursos, desde las distintas voces que resuenan en la novela, generando a su vez, "efectos de lugar" (Bourdieu, 1999: 119-124), esto es que "el espacio se manifiesta en los contextos más diversos, en la forma de oposiciones espaciales, en las 
que el espacio habitado (o apropiado) funciona como una especie de simbolización espontánea del espacio social. [... ] no hay espacio que no esté jerarquizado y no exprese las jerarquías y las distancias sociales" (Bourdieu, 1999: 120).

Se entiende entonces que el texto de ficción es un espacio referencial saturado de los puntos de vista ideológico y cultural, tanto del autor como de los personajes y narrador(es). Estos puntos de vista se manifiestan en las posiciones (espacio habitado/apropiado en la lógica interna del texto) jerarquizadas y, por lo tanto, cargadas de toda una simbólica en el espacio social textual.

Con todo lo anteriormente expuesto, pareciera como si no existiera una diferencia entre realidad y ficción. Sin embargo a diferencia de un texto susceptible de ser corroborado (testimonial, periodístico, sociohistórico, científico, etcétera), esto es, que se rige a partir del criterio de verdad, la literatura de ficción se fundamenta en el principio de verosimilitud, entendida como un "rasgo de la obra de arte verbal, que consiste en la apariencia o ilusión de realidad que provocan determinadas obras en el lector o espectador, dado el carácter mimético de las mismas" (Beristáin, 2003c: 491-494). Por ello, toda obra de ficción es una poiesis, ya que no sólo crea y recrea sino simboliza: al crear y recrear vuelve símbolo lo que está contenido en el texto de ficción. ${ }^{6}$ Por lo tanto, el "texto de ficción no nos da una información como nos la puede dar una documentación periodística, sino que nos la da gracias a su capacidad específica de acumular información" (Cros, 1986: 71): cada novela concentra en un espacio ficticio prácticas cotidianas y

\footnotetext{
${ }^{6}$ Según Demetrio Estebanéz, la mímesis, para Paul Ricœur, puede equipararse a poiesis: "en la Poética de Aristóteles el sentido de la 'mímesis' (imitación) no sería el de reproducción dela realidad, sino el de representación, entendida como creación artística de una nueva realidad. [... ] 'mímesis' sería sinónimo de 'poiesis', es decir, de creación y de ordenación de las acciones que constituyen una determinada fábula. Este concepto de 'mímesis' se adecuaría a lo que hoy se entiende como ficción: creación y estructuración de 'mundos posibles' [... ] basán dose en el principio de verosimilitud, lo que implica que su constitución sigue las reglas que gobiernan la organización del mundo real. Pero dicha verosimilitud consistiría [... ], en ser un mundo posible autónomo, creado, [... ] con una lógica de composición similar a la que rige en el mundo real, siendo como es ente de ficción" (Estebanéz, 2006: 411-412).
} 
representaciones heteróclitas vividas desde sus personajes en un máximo de economía.

Algunos de los textos de ficción fueron escritos por ex guerrilleros (Salvador Castañeda, Ramón Gil, Gustavo Hirales), periodistas (Juan Miguel de Mora, René Avilés Fabila) o familiares (Fritz Glockner), por mencionar sólo algunos; o bien, por escritores consagrados como es el caso de Carlos Montemayor, quien utilizó recursos como material periodístico e histórico/testimonial, resultado de las investigaciones hechas por él mismo (grabaciones, documentos y archivos) para escribir sus novelas. En este sentido, las novelas no pueden tomarse como un referente meramente testimonial, histórico o periodístico, ya que el recurso narrativo del que se vale cada uno de los autores es la ficción, aun cuando éstos mezclen elementos testificantes o susceptibles de ser corroborados. En su lugar, se crea un analogon del mundo real. El texto hace como si remitiera a algo extratextual, es decir, a algo "constituido por la historia, la cultura y los otros textos contemporáneos, ajenos o propios del autor" (Beristáin, 2003b: 206); pero que no es más que una simulación (Robin, 2001: 272). ${ }^{7}$

En el caso del texto artístico, la singularidad del escritor se anula al momento en que éste logra distanciarse y objetivar los elementos testificantes o corroborables, al someterlos a la lógica de la intriga en la creación artística para hacer de su historia algo verosímil. Dicho de otro modo, las narrativas de ficción rompen con el orden (lógica) histórico y cronológico para reelaborar un entramado de relaciones que constituyen el orden artístico, el orden de la intriga, es decir, el orden de la historia, aun cuando las historias narradas estén imbricadas de elementos testificantes (incluso de cualquier documento verificable) pues éstos tampoco escapan al orden de la ficción.

Así pues, los autores, sean ex guerrilleros, periodistas o escritores (estos últimos consagrados en el campo literario), ponen en juego, a través de sus personajes, espacios y tiempos, todo un sistema de relaciones que configuran una realidad social textual capaz de dar razón

\footnotetext{
${ }^{7}$ Es una simulación (aun en el realismo) porque los referentes culturales, históricos, etcétera, también son ficción, pero, en este caso, es hacer lo irreal verosímil por medio de la argumentación; esta es la realización de la representación mimética de Paul Ricœur.
} 
de un espacio social como si fuera un mundo posible, pues "la realidad que trata de cernir [el escritor] no se deja reducir a los datos inmediatos de la experiencia sensible en los que se revela; no se propone hacer ver, o sentir, sino construir unos sistemas de relación inteligibles capaces de dar razón de los datos sensibles" (Bourdieu, 1997: 43). En otras palabras, el escritor no vacía en la hoja en blanco su experiencia inmediata. Por el contrario, el escritor "anula" su "singularidad" en el momento en que la información verificable se mezcla con la ficción para construir una intriga, con personajes y espacios igualmente ficticios, que den razón de un conjunto de signos capaces de hacer que el mensaje sea significativo para el lector.

Hasta aquí se ha visto el vínculo sociocultural que el texto de ficción mantiene con el mundo, caracterización que abre el camino para acercarse a la novela como una unidad autónoma en relación con su propio autor. Para profundizar en este punto se echará mano de la categoría de polifonía de Bajtin (2003).

Como ya se indicó, cada escritor (como individuo histórico/ biográfico) mantiene una relación inmanente con su propia experiencia. Agrego aquí, sin ahondar, que éste porta una intencionalidad al momento de recrear las realidades literarias, sin embargo, el escritor se diferencia y distancia de su ser guerrillero, periodista, representante político, etcétera, para convertirse en el autor/emisor. Tal diferenciación y distanciamiento sucede cuando el autor logra incorporar en el narrador y sus personajes diversas voces de su lengua aprendida y asimilada en una comunidad de voces habladas, para representar una comunicación socialmente establecida y atravesada por numerosas variaciones en los diálogos. En esta diversidad de diálogos están siempre presentes el encuentro (intersección), la similitud (concordancia) y la objeción (interrupción) de los argumentos o réplicas de un diálogo abierto mediante las réplicas del diálogo interno de los personajes (Bajtin, 2003). De esta manera, las palabras que el autor va plasmando aparecen en todo el texto singularizando las varias voces para diferenciarlas y distanciarlas (sin llegar a desarticularlas: cada autor parte invariablemente del mismo principio de estructuración en sus novelas, en este caso, la guerra sucia y las guerrillas urbanas): 
La estratificación interna de una lengua nacional en dialectos sociales en grupos, argots profesionales, lenguajes de género; lenguajes de generaciones, de edades de corrientes; lenguajes de autoridades de círculos y modas pasajeros; lenguajes de los días, e incluso de las horas; social-políticos (cada día tiene su lema, su vocabulario, sus acentos); así como la estratificación interna de una lengua en cada momento de su existencia histórica, constituye la premisa básica para el género novelesco (Bajtin, 2001a: 60).

Esa comunidad de la que también es producto el autor, resultado de individuos en relación y producción de sentido, se concreta de manera similar "en un producto cultural significante y estable" (Bajtin, 2003: 16). El autor recrea una totalidad de sentido estable y necesaria dentro de la obra a partir de las representaciones y prácticas de sus personajes, que dan vida a un espacio social singular y contenido de referencias culturales que crean un mosaico de experiencias resemantizadas para reformular las representaciones social mente establecidas de las guerrillas mexicanas: la abundancia del mundo, las aventuras y dificultades narradas y practicadas en el texto, y la perspectiva o puntos de vista de cada personaje están diseminados estéticamente en toda la novela para dar vida al espacio social en que se desarrollaron las guerrillas durante la década de los setenta.

De esta manera, la idea de polifonía alu de a la mezcla de las distintas voces y discursos socio-culturales que habitan y se interfieren en la novela. El despliegue, cruce, o bien, conflictos entre las voces tanto del autor como del narrador y sus personajes presentes en cada novela, se torna un punto de vista diversificado sobre la guerra sucia y las guerrillas urbanas, según el punto en que se sitúa el autor, el narrador y los personajes en el espacio social recreado en la novela; y, al mismo tiempo, este carácter pluridiscursivo es, además, lo que dota a cada una de las novelas de guerrilla de su cualidad irresoluble y conflictiva, pues la novela polifónica es polémica, ambigua y contradictoria, irónica, paródica y contestataria de su propia realidad. De ahí entonces, el distanciamiento y autonomización de la obra respecto a su autor: el punto de vista 
de cada autor es también un espacio creado/inventado a partir de una diversidad de voces culturales que combina estéticamente los segmentos de la sociedad a la que pertenece. Cada autor es un punto de vista, así como el narrador y sus personajes configuran una realidad textual compleja, diferenciada y segmentada, y en la que se establece el anudamiento de un conjunto determinado de relaciones sociales para recrear una totalidad estable y necesaria en la realidad social textual. Cada uno de los personajes es representativo de ese particular nudo en el entretejido narrado, que si bien están diferenciados e incluso llegan a aparecer distantes entre éstos, para el lector no están desarticulados sino organizados alrededor de la guerra sucia y sus guerrillas recreadas artísticamente.

Asimismo, me ocuparé de otra categoría bajtiniana para los propósitos de este artículo. Se trata del cronotopo (Bajtin, 2001b), el cual se refiere a las conexiones espaciales y temporales desarrolladas estéticamente en el texto de ficción. En este sentido, tanto la forma como el contenido en la novela se definen a partir del cronotopo: lo que se desprende del cronotopo bajtiniano, es que éste define el género artístico-literario. El cronotopo establece tanto la forma y el contenido, como la imagen y psicología de los personajes al ser asimilados en la intersección de los elementos espaciales y temporales condensados en la narración de la historia de ficción. Esta asimilación, a su vez, condensa el cronotopo histórico real, para ser reelaborado, transformado y constituido en una entidad distinta y singular: el cronotopo artístico. Y éste, a su vez, condensa las acciones plasmadas en la novela de manera figurativa, pues el tiempo de la novela se materializa en el espacio (Bajtin, 2001b: 63); el "tiempo adquiere un carácter concreto-sensitivo; en el cronotopo se concretan los acontecimientos argumentales, adquieren cuerpo, se llenan de vida. [... ] Es el cronotopo el que ofrece el campo principal para la representación en imágenes de los acontecimientos" (Bajtin, 2001b: 67).

De ahí que el espacio social de las guerrillas mexicanas de los setenta que plasma cada autor en su novela no se reduce a los datos inmediatos de la experiencia vivida o verificable, sino que tal realidad histórica es recreada y resemantizada en un sistema de relaciones inteligibles que adquieren un carácter concreto-sensitivo a partir del 
cronotopo artístico, el cual, efectivamente, condensa la acción de los guerrilleros y sus oponentes en la novela de manera figurativa y da razón, al mismo tiempo, de los datos sensibles; esto es, la forma y el contenido, así como la imagen y psicología de los personajes amalgamados con el tiempo y el espacio de la historia novelada. Con el cronotopo, tal producción pluridiscursiva o polifónica en la(s) novela(s) de guerrilla en México, es el poder que éstas tienen para condensar información en un máximo de economía, si se considera desde una perspectiva sociológica.

En resumen, se puede decir que durante el proceso de reelaboración de cualquier realidad novelada, el autor pone en juego las distintas representaciones que de ésta tiene y a partir del particular nudo del entretejido social al que pertenece. Esto hace del texto novelístico "un foco cultural muy poderoso" (Robin, 2001: 263) susceptible de ser estudiado sociológicamente. Esta producción y recreación de un mundo social y de las representaciones plasmadas en la novela no aparecen de manera diáfana ni coherente; tampoco aparecen bajo la lógica de la demostración científica o histórica, pues la novela no demuestra: muestra y evoca, junto con el lector, una realidad ficcional o textual que "no expresa la historia o lo social en una transparencia ilusoria de los signos, sino que interroga, evalúa, inscribe su cortejo de interrogaciones angustiadas en contra de un discurso pleno, explicativo, que no deja nada al azar y orienta hacia el futuro" (Robin, 2001: 296). Esta "realidad" que existe dentro del texto estético se vigoriza a partir de voces y rumores que hacen de la palabra escrita representaciones polifónicas, que

[M ]ás que objetos de la palabra del autor, se nos presentan como sujetos de sus propios discursos, como una pluralidad de conciencias autónomas con sus correspondientes concepciones del mundo, cuyos caracteres y destinos, lejos de diluirse en la unitaria conciencia del autor, forman parte de un entramado de voces y posiciones ideológicas en una especie de contrapunto musical, del cual se deriva la metáfora bajtiniana de la polifonía narrativa (SánchezMesa, 1996: 203). 
Con lo dicho hasta aquí, se puede entonces comenzar esta sección señalando que la coyuntura política e histórica en que se enclavan las novelas de guerrilla urbana y la guerra sucia, determina también la trascendencia sociohistórica que dicha producción representa en la actualidad, pues una gran parte de esas novelas se escribió y publicó bajo el mismo contexto de la represión y autoritarismo del Estado; esto es, durante la guerra sucia y la criminalización o el silencio de los medios de comunicación de masas, así como también en medio de la omisión histórica de dichos movimientos en los espacios de producción de conocimiento.

El problema que se desprende de las afirmaciones expuestas arriba, puede entenderse si se parte de que el sentido social e históricamente estructurado precisamente se "naturaliza" en los individuos o colectivos a partir de las representaciones sociales válidas en un espacio social determinado y organizado jerárquicamente en un sistema de oposiciones. Para que esto se realice es necesario

que muchas prácticas culturales se concentren en 0 al rededor de poderosos nudos institucionales que incluyen las religiones, los medios de comunicación, las corporaciones de negocios y [... ] los estados. Dichas instituciones, con tendencias de escala relativamente amplia, centralizadas y ricas, son en su totalidad actores culturales; sus agentes invierten continuamente considerables recursos en sus esfuerzos por ordenar los significados (Sewell, 2005: 394).

Siguiendo las ideas del autor, tal ordenamiento está dirigido a organizar la diferencia, a jerarquizar, excluir, marginar, criminalizar, hegemonizar o encapsular todo aquello que se desvíe del ideal sancionado (2005: 395). Esto es,

[C]uando los actores dotados de autoridad distinguen [... ] entre prácticas legales y criminales, o entre lo normal y lo 
anormal, están introduciendo prácticas muy variadas [en] un campo semiótico y políticamente ordenado de diferencias. [... ] Tal acción crea un mapa de la "cultura" y sus variantes, un mapa que muestra a la gente cuál es su lugar, juntamente con sus prácticas, dentro del esquema oficial de las cosas. (Sewell, 2005: 395).

De esta manera, la existencia de un sistema semiótico y de oposición supone la legitimidad y el reconocimiento de las representaciones que configuran una cultura: son percibidos, aprendidos, asumidos, aceptados y/o rechazados en una suerte de naturalización del espacio social, lo que produce un acuerdo tácito compartido de dicho sistema de oposición: justo/injusto, bueno/malo, legítimo/ilegítimo, legal/ilegal, etcétera. Con esto se asume aquí que la cultura clasifica, organiza y distribuye al ser humano y a la naturaleza. Este proceso de clasificación y nominación implica también excluir, marginar, segregar, discriminar (xenofobia, racismo, clasismo, etcétera) o hasta asesinar, pues impone de manera efectiva definiciones que ordenan a los individuos o grupos, y además generan contradicciones y conflictos entre éstos.

Lo anterior es homologable con la idea de estrategia que propone de Certeau (2000), a saber: "Llamo estrategia al cálculo (o a la manipulación) de las relaciones de fuerzas que se hace posible desde que un sujeto de voluntad y de poder (una empresa, un ejército, una ciudad, una institución científica) resulta aislable" (de Certeau, 2000: 42). Este aislamiento de las instituciones que concentran y ordenan las diferencias, postulan un lugar susceptible de ser circunscrito como algo propio. A partir de este lugar es que se pueden organizar y administrar las estrategias o los varios recursos que estas instituciones invierten para amenazar o distanciar cualquier el emento de exterioridad. Así pues, las instituciones que concentran el poder establecen un espacio propio, un lugar con toda una lógica simbólica y desde el cual jerarquizan, censuran, controlan e incluso destruyen a todo aquello que ponga en riesgo dicho poder. La instauración de un lugar propio y, en consecuencia, de un lugar ajeno al ciudadano común, implica las siguientes consecuencias (de Certeau, 2000: 42-43): lo propio establece una victoria sobre el tiempo, esto permite capitalizar los recursos y 
ventajas para delimitar el espacio de los futuros posibles, y establecer cierto grado de independencia en relación con la variabilidad de las circunstancias; asimismo, lo propio permite el dominio de los lugares mediante la vista, pues el ordenamiento del espacio permite la vigilancia desde las instituciones dominantes donde todo aquello que se desvíe del ideal definido, se pueda observar y medir para ser controlado, castigado o destruido; y, por último,

Sería legítimo definir el poder del conocimiento por medio de esta capacidad de transformar las incertidumbres de la historia en espacios legibles. Pero es más exacto reconocer en estas "estrategias" un tipo específico de conocimiento, el que sustenta y determina el poder de darse un lugar propio. Además las estrategias militares o científicas siempre se han iniciado gracias a la constitución de campos "propios" (ciudades autónomas, instituciones "neutras" 0 "independientes", [...]). Dicho de otra forma, un poder es la condición previa del conocimiento, y no sólo su efecto 0 atributo. Permite e impone sus características. Ahí se produce (de Certeau, 2000: 43).

Por ello, ninguna condición de exterioridad (continúa de Certeau, 2000: 43) le proporciona autonomía a los ciudadanos, pues el lugar en que se mueven es el lugar que se les impone como la ley de las instituciones dominantes; lugar al que los ciudadanos no tienen alcance. "La racionalidad política, económica o científica se construye de acuerdo con este modelo estratégico" (de Certeau, 2000: L).

En síntesis, se puede decir que las "estrategias son pues acciones que, gracias al principio de un lugar de poder (la propiedad [apropiación] de un lugar propio), elaboran lugares teóricos (sistemas y discursos totalizadores) capaces de articular un conjunto de lugares donde se reparten las fuerzas" (de Certeau, 2000: 45).

Partiendo de lo anterior, es posible afirmar que los actores culturales como las instituciones eclesiásticas, las corporaciones económicas y los medios de comunicación centralizaron e invirtieron considerables 
recursos para distribuir y legitimar categorías criminalizantes que negaron las cualidades socio-políticas de las guerrillas urbanas, lo que dio como resultado que éstas fueran sometidas a una lógica silente, principalmente en la escritura de la historia y en los espacios en que se produce el conocimiento académico (explicar sociológicamente este tipo de silencio es materia pendiente, basta decir aquí que no fue únicamente resultado de la censura y clandestinidad que el Estado impuso y que los mismos guerrilleros necesitaron para su mantenimiento); esto es, al dotarlos de coherencia en el mapa cultural de dicho periodo al momento de clasificarlos como criminales, terroristas y transgresores de la ley, simultáneamente fueron negados, silenciados o censurados como movimientos sociales armados de tendencia socialista.

Por otro lado, las formas de acción colectiva utilizadas por las guerrillas urbanas (la lógica militar, armada, y la violencia organizada), fueron cualidades de las que se valió el Estado mexicano para legitimar y justificar el uso de prácticas represivas (silenciosas y clandestinas de persecución, encarcelamiento, asesinato y desaparición) en contra de los guerrilleros.

En consecuencia, apareció el "efecto destino que produce la categorización estigmatizante" (Bourdieu, 2005: 144). Este efecto destino, estructurado a partir de "categorías de percepción rectas (straight, en oposición a crooked, torcido, como en la visión mediterránea)" (Bourdieu, 2004: 144), no sólo fue resultado, sino también fue un elemento generador (bajo el contexto de la Guerra fría) y legitimador de un lugar propio que el Estado capitalizó para proyectar dichas categorías o representaciones a futuro más allá de las circunstancias, 0 aprovechándolas a lo largo del devenir del tiempo. El Estado y sus instituciones dominaron el lugar y el tiempo, lo cual se tradujo en la definición de la identidad de los enemigos del Estado en la organización social del sentido, manteniendo con esto la idea de unidad y orden social en los discursos nacionales.

La realidad de los hechos durante la guerra sucia fue sometida a la clandestinidad, a la ausencia de registros o desaparición de información que pudiera ser verificable en relación con las prácticas emprendidas 
por los aparatos coercitivos del Estado. La lógica de la desaparición de información y, peor aún, de personas, dotó material y simbólicamente al Estado de un aparente control total del tiempo y el espacio. Esto garantizó que la cuadrícula espacio temporal o el campo semiótico de la cultura organizado a partir de las diferencias significativas entre el ideal aceptado y el ideal sancionado, entre lo straight (recto) y lo crooked (torcido), se impusieran en las estructuras cognitivas de grupos e individuos en el espacio social, clausurando (durante treinta años) cualquier posibilidad de hacer visible en el espacio público lo sucedido durante la guerra sucia.

Así pues, el dominio estratégico sobre el espacio adoptó, en este caso, formas muy singulares, pues la inclusión de lo amenazante o lo extraño bajo las categorías criminalizantes que hicieron perceptibles a esos movimientos armados, equivalió a representar las violaciones del Estado como actos o castigos ejemplares aplicados a dichos movimientos ya que éstos, desde la lógica estatal, rebasaron los límites impuestos y, en consecuencia, tolerados por el Estado, siendo, en términos de la "naturalización" (creencia) de dichas representaciones, los mismos guerrilleros "responsables de su destino" al no respetar "los principios de la sociedad mexicana" ni ser "leales a la patria". Así pues, en los medios de comunicación se desplegó una campaña de deslegitimación y negación (incluso bajo una lógica del secreto a voces), que logró encubrir a dichos movimientos con un velo de mensajes ambivalentes, contradictorios y estigmatizantes.

Asimismo, la estrategia del dominio sobre el conocimiento se establece a partir de un poder que tiene la capacidad de generar un campo propio. Es decir, no sólo se ejerce el poder por medio del conocimiento, sino el mismo poder es la condición de posibilidad para que determinados conocimientos se generen en, y sean generadores de lugares específicos. De ahí pues, que esta lógica facilitara el silencio de los hechos ocurridos durante ese periodo. No sólo el Estado se movió en una suerte de plano irreal contra el que aparentemente no se puede luchar, sino también las instituciones escolares reprodujeron el punto de vista del dominante al reproducir el olvido y silencio en las investigaciones de la época. 
Sin embargo, tal partición del tiempo y el espacio en una suerte de cuadrícula (o mapa cultural, Sewell, 2005) no se impone de manera absoluta y cerrada al ciudadano común, pues las situaciones contingentes se presentan al ciudadano como posibilidades. Este es el momento (lugar y tiempo) en que el ciudadano construye lo que de Certeau (2000) denomina tácticas, las cuales corresponden a las prácticas en función de los intereses del ciudadano común. Estas tácticas se entienden aquí como "la acción calculada que determina la ausencia de un lugar propio" (2000: 42-43). Es la carencia de un lugar propio, "sin visión globalizadora, ciega y perspicaz como sucede en el cuerpo a cuerpo sin distancia, gobernada por los azares del tiempo, la táctica se encuentra determinada por la ausencia de poder" (de Certeau, 2000: 44. [cursivas del autor]).

En esta cuadrícula o mapa de la cultura, el ciudadano común no tiene el dominio de la lógica espacio temporal. Sin embargo, éste no se halla completamente controlado o sometido pues ni la racionalidad del Estado ni la racionalidad científica logran el dominio total sobre el espacio y el tiempo. En este sentido, el individuo aprovecha las situaciones contingentes como si fueran una "ocasión" (de Certeau, 2000: 43-44), pues depende de ésta. En la ocasión es cuando "la astucia es posible al débil, y a menudo ella sola, como un último recurso" (de Certeau, 2000: 44). En otras palabras, los individuos se las arreglan para escapar a la lógica impuesta y "convertir la posición del más débil en la más fuerte" (de Certeau, 2000: 44).

A esta capacidad que tienen los ciudadanos comunes de "ap rovechar la ocasión" (de Certeau, 2000: L), de usar la "astucia" (2000: 45) y de escapar a la visión de los grupos dominantes, de Certeau le llama "el arte de dar buenas pasadas" (2000: 44); esto es, usar la astucia para tomar al vuelo la ocasión que ofrece el instante para escapar de los mecanismos de poder controlados por las instituciones y reapropiarse "del espacio organizado por los técnicos de la producción sociocultural" (2000: XLIV). De esta manera, los individuos se las arreglan para escapar a la lógica impuesta: tiempos y lugares, sus lógicas y significados; se las arreglan para escapar de las representaciones impuestas como la norma con que se miden todas las cosas. Por ello, dice de Certeau, "hace falta valerse de" (2000: 35-48). Así pues, las "tácticas son 
procedimientos que valen por la pertinencia que dan al tiempo: en las circunstancias que el instante preciso de una intervención transforma en situación favorable" (de Certeau, 2000: 45).

\section{Sobre LA NOVELA DE GUERRILLA Y EL ARTE DE LAS BUENAS PASADAS}

Con lo visto hasta aquí se puede guiar la discusión hacia mi propósito: demostrar que la producción estética en torno a las guerrillas del siglo pasado insinúa (insinuer) un poder que tiene la capacidad de producir vacíos en la historia para transformarlos en espacios legibles (durante su lectura) al incorporar en las narraciones las experiencias y la palabra hablada en los procesos de textualización.

Se puede decir entonces que en las relaciones de fuerzas impuestas sobre el tiempo y el espacio se introduce una forma de inteligencia práctica bajo la lógica del disimulo, y cierta invisibilidad respecto a los discursos dominantes de la época. Esta forma de practicar el espacio y el tiempo se traduce en una práctica estética que no expresa un movimiento en la cuadrícula impuesta o una confrontación franca en el mapa cultural, sino lo hace propiamente con el sentido de la ocasión. Es decir, aunque la constitución de un tiempo y espacio en la novela es ficticio, esta forma de narrar un periodo silenciado es una táctica que se insinúa (insinuer) en el lector: no sólo las realidades estéticas penetran en el ánimo del lector, sino también esos textos se introducen en el espacio físico (social) dominante. Nuestras novelas de guerrilla al ser leídas estimulan y movilizan los referentes que dotan de sentido en el presente (del lector) a las guerrillas urbanas y la guerra sucia en el espacio social (real) y, al mismo tiempo, se introducen en el orden del mapa cultural para crear los intersticios (lugares ambivalentes, contradictorios o silenciados) que han predominado en la historia y los discursos dominantes y transformarlos en espacios legibles. Es posible afirmar, pues, que esta transformación, esta "mutación hace habitable el texto como si fuera un apartamento rentado. Transforma la propiedad del otro en lugar que, por un momento, un transeúnte toma prestado" (de Certeau, 2000: LII). 
Por ello, la configuración de una realidad social textual en las novelas de guerrilla en México, significa también la constitución de un poder que confiere a la novela y a las guerrillas un conocimiento susceptible de ser usado y ocupado por el lector. De esta manera, si se entiende "el poder del conocimiento [como] esta capacidad de transformar las incertidumbres de la historia en espacios legibles" (de Certeau, 2000: 43), se puede decir entonces que esas novelas constituyen un espacio que tiene el poder del conocimiento; que tienen la capacidad de concentrar las maneras de hacer de las lógicas de las guerrillas y la guerra sucia y transformar las incertidumbres de la historia en espacios legibles, es decir,

En la medida que son signos de singularidades - murmullos poéticos o trágicos de lo cotidiano-, las maneras de hacer se introducen masivamente en la novela o las narraciones [... ]. Ahí encuentran un nuevo espacio de representación, el de la ficción, poblado por virtuosidades cotidianas cuya ciencia no sabe sino hacer y se convierten, del todo reconocibles por parte de los lectores, en firmas de microhistorias de todo el mundo. La literatura se transforma de esta forma en un repertorio de estas prácticas (de Certeau: 80).

Tematizar la guerra sucia en los textos de ficción introduce un pasado vigente en la construcción histórica y postula un lugar contestatario de la realidad objetivada en la novela. El relato a su vez insinúa en el mapa semiótico dominante la denuncia de la represión emprendida por el Estado y experimentada por los guerrilleros. Estas son "[m]il maneras de hacer/deshacer el juego del otro, es decir, el espacio instituido por otros, caracterizan la actividad, sutil, tenaz, resistente, de grupos que, por no tener un lugar propio, deben arreglárselas en una red de fuerzas y de representaciones establecidas. Hace falta 'valerse de"' (de Certeau, 2000: 22).

Entendidas, pues, como una manera de hacer una buena pasada en un espacio que les es ajeno, las novelas de guerrilla se introducen en la relación de fuerzas impuesta por el mapa cultural. Esta forma de hacer 
una buena pasada sucede gracias al principio de economía: "con el mínimo de fuerzas, obtener los máximos efectos" (de Certeau, 2000: 92). Entonces, ¿cómo es que las novelas de guerrilla logran decir lo que los discursos políticos y científicos dominantes no dicen, utilizando un mínimo de fuerzas para obtener los máximos efectos?

La capacidad de acumular información de la novela que el escritor crea y el lector recrea, no aparece de manera diáfana, sino a manera de poeisis, es decir, vuelve símbolo los elementos referenciales contenidos en el texto. Esta estructuración mimética del discurso logra formar en el pensamiento, a través del principio de verosimilitud, una realidad social que sigue las lógicas que gobiernan la organización del mundo real y dotado de sentido en y por las representaciones sociales de los individuos. Esta realidad creada por el escritor es un mundo posible que alude a la simulación, a la ilusión de la realidad; dice sin decir, pues habla de la realidad fingiendo y es a su vez un ente de ficción autónomo contestatario y paródico de su propia realidad.

En este mismo sentido, los discursos plasmados en la novela parten del principio de economía que densifica y distribuye la información, sea ficticia, sea testimonial, para trazar durante la creación estética el cronotopo y la polifonía literaria. Supone también la mediación de conocimientos particulares diseminados a lo largo de la novela a manera de muchos momentos y muchos elementos diferenciados y distanciados entre sí, pero organizad os a partir de un eje estructurante que es el tema de la novela: la guerra sucia y las guerrillas urbanas; las intersecciones de las series y uniones de esos momentos y elementos constituyen el cronotopo y logran una efectiva economización de las prácticas representadas en la novela. Es decir, las fuerzas invertidas disminuyen, pero el conocimiento/memoria aumenta y densifica en un tiempo reducido para aumentar los efectos reconocidos por los mismos lectores (de Certeau, 2000: 93).

Lograr con ello más efectos con menos fuerzas, es una "jugada", como de Certeau la Ilama, la cual, además, funciona como mediación del conocimiento, pero un conocimiento que no cuenta con un lugar ni un espacio propios, sino es un tipo de memoria, cuyos conocimientos son inseparables de su propio decir y de las prácticas narradas en la novela. Esta memoria aparece como 
Informada por una multitud de acontecimientos donde circula sin poseerlos (cada uno de ellos es pasado, pérdida de lugar, pero fragmento del tiempo), calcula y prevé también "las vías últimas del porvenir" al combinar las particularidades antecedentes o posibles. Una duración se introduce así en la relación de fuerzas, una duración que va a cambiarla [... ], que le resulta favorable, contra una composición de lugar, que le resulta desfavorable (de Certeau, 2000: 92).

Tal creación estética diluye la información contenida en la novela: aquí ya no hay ruptura ni distinción entre ficción/realidad/historia/ testimonio. Por el contrario, toda esta unidad que es la obra funde en un solo objeto las intenciones del autor y las conciencias de cada personaje dotados de autonomía en el cronotopo. Es entonces que dicha economía de la novela se concreta en los elementos establecidos en el interior del texto por el autor. Tal estructuración, en síntesis, establece el nivel interno de la obra aunque parece que remite a al go extratextual, haciendo de la información resemantizada en el texto una forma de conocimiento singular que resulta de la poiesis, tiempo y lugar que define la denotación y connotación ${ }^{8}$ de los elementos que gobiernan la organización del espacio social estructurado en la novela, distanciado e incluso ajeno al autor. Pero, esta memoria aparece sólo en la medida en que se le revela al lector, esto es, en el momento oportuno, digámoslo así: "El resplandor de esta memoria brilla en la ocasión" (de Certeau, 2000: 93), y hace de esta ocasión una relación de fuerzas favorable, aun cuando las condiciones políticas, sociales e históricas sean contrarias.

\footnotetext{
${ }^{8}$ En términos generales, en los estudios literarios, la connotación "se emparejay opone desde siempre a la denotación [... ], en cuanto indica una serie de valores secundarios, no siempre bien definidos y en al gunos casos extralingüísticos, ligados en ciertas ocasiones a un signo, bien para un grupo de hablantes, bien para uno solo. Así zorro tiene un significado denotativo [... ] (animal mamífero de la familia de los cánidos); pero tiene también un valor connotativo, cuando, metafóricamente, se refiere a una persona: 'es un zorro' puede querer decir que es astuto, pero también que es hipócrita" (Marchese y Forradellas, 2006: 75-76). Esto quiere decir que en un primer plano, el dela denotación, existe el paso a un segundo nivel de significación: la connotación.
} 
De esta manera, el lector moviliza y actualiza tales representaciones estructurantes de la memoria para comprometer en su lectura la denotación y connotación necesarias en los procesos de significación del mensaje para dotar de sentido(s) las experiencias y realidades evocadas y mimetizadas en el texto de ficción. Tales conversiones de la memoria, que a manera de conocimiento se singulariza en la novela, escapan a la racionalidad del dominante al utilizar formas discursivas distorsionadas y ficticias que producen una ruptura instauradora y transgreden en el momento oportuno la lógica del tiempo y el espacio históricos, dotando simultáneamente de distintos significados a las guerrillas urbanas y a la guerra sucia del México de los setenta. La lectura de dichas ficciones se convierte así en el momento oportuno porque actualiza un pasado ambiguo en la historia mexicana.

Dicho de otro modo, las novelas de guerrilla plantean tácitamente el espacio social y el tiempo en una diversidad de prácticas textuales mediante los discursos explícitos inmersos en las novelas. Esto origina diferentes interpretaciones que funcionan como una red de operaciones trazadas por los personajes y cuyas formas de ser representados crean "las buenas pasadas", pues sus propias acciones y discursos son los que estimulan los procesos de significación en la memoria de los individuos; son pues las propias acciones de los personajes las que significan. Esta inversión, economía y conversión de las prácticas establece una paradoja: Ias novelas que tematizan la guerra sucia y sus guerrillas hacen como si fingieran una realidad, es decir, dicen como si no dijeran, sin embargo, al mismo tiempo, ponen en cuestión o duda el orden simbólico pasado y vigente en relación con las guerrillas urbanas de los setenta. Por ello, sostengo aquí que los vacíos en la historia no están ahí en sí mismos y en espera de ser descubiertos. Por el contrario, esta forma de narrar la guerra sucia escapa a la lógica del dominante y construye diversos sentidos en torno a experiencias significativas durante la década de los setenta. La narrativa de ficción en torno a estos movimientos sociales es una forma de escaramuza que burla la distribución de significados en el espacio público y la cual se insinúa en los referentes de los individuos, dislocando las definiciones dominantes y dotando de sentido lo que los discursos dominantes no dicen sobre estos 
movimientos: es entonces que se producen los vacíos históricos y se evidencian en el espacio público.

\section{CONCLUSIONES}

Hasta aquí se puede decir entonces que, a pesar de las estrategias del Estado, la publicación desde los años setenta y hasta la fecha de una serie de novelas que tienen como tema central las guerrillas urbanas de dicha década, ha significado la construcción de otras maneras de decir que dan cuenta de una realidad política y social omitida históricamente. Esta táctica emprendida por el escritor, a manera de buena pasada, logra decir fingiendo o simulando los mecanismos de represión y asesinato utilizad os durante la guerra sucia, pues, como señala de Certeau (2000), existen otras lógicas discursivas que permiten al débil el arte de hacer buenas pasadas: los relatos, los mitos, las leyendas, las fábulas, la ficción, los milagros, etcétera.

Ese arte de dar una buena pasada, se concreta cuando el conocimiento singularizado en las novelas, cuando la memoria narrada es significada por los lectores para establecer, sin confesarlo, el sentido de la ocasión. Cada novela logra establecer una ruptura restauradora a partir de la lógica del discurso de ficción en torno a las guerrillas urbanas de los setenta en M éxico, e introduce un poder que tiene la capacidad de crear los vacíos históricos, nombrarlos y transformarlos en espacios legibles. Esto potencia y moviliza la (re)significación de la memoria colectiva mediante las realidades textuales configuradas en la literatura de ficción. En este sentido es que las guerrillas y la guerra sucia se apropian de un espacio simbólico significativo y en oposición a los discursos dominantes de dicho periodo. Más todavía, la (re)significación de la memoria colectiva implica a su vez (re)alimentar la escritura de la historia, pues finalmente ésta es una de las funciones que tiene la memoria colectiva en la reconstrucción histórica. De ahí también que la novela sea práctica, producto y objeto social.

En resumen y para terminar, el poder de las novelas de guerrilla en México es un poder que se constituye bajo otra lógica discursiva, bajo 
una lógica de poder hacer una buena pasada al apropiarse con base en la ficción de espacios y tiempos que le permiten construir un saber sobre el dominante y, al mismo tiempo, escapar a la lógica impuesta (cuadrícula espacio/temporal o como un ordenamiento de las diferencias en una especie de mapa coherente de la cultura), pues las novelas de guerrilla descubren relaciones y vínculos sociales que fueron encubiertos por los discursos oficiales/circulantes de no hace mucho tiempo. Por ello, el poder que instaura la lógica del discurso de ficción al rededor de las guerrillas de los setenta, es un poder que tiene, por un lado, la capacidad de establecer/instaurar vacíos históricos y, por el otro, tiene la cualidad de transformar las incertidumbres de la historia en espacios legibles. Es a través del texto de ficción que las guerrillas se han apropiado (ocupado) de un lugar. Ese es el poder de los espacios legibles: la inmanencia durante la escritura y lectura de esos textos es irresoluble, conflictiva, polémica, irónica, paródica y contestataria de su propia realidad. Es en este sentido que hablo del arte de hacer una buena pasada.

\section{FuENTES CONSULTADAS}

Bajtin, M. (2001a), "La palabra en la novela”, en Enric Sullà (comp.), Teoría de la novela: antología de textos del siglo Xx, 2a ed., Barcelona: Crítica, pp. 59-62.

(2001b), "El cronotopo", en Enric Sullà (comp.), Teoría de la novela: antología de textos del siglo xx, 2a ed., Barcelona: Crítica, pp. 63-68.

(2003), Estética de la creación verbal, 11a ed., México: Siglo $X X I$.

Beristáln, H. (2003a), "Autor", voz en Diccionario de retórica y poética, $8 a$ ed. (4a reimpr.), M éxico: Porrúa, p. 70.

(2003b), "Extratextualidad", voz en Diccionario de retórica y poética, 8a ed. (4a reimpr.), México: Porrúa, p. 206.

(2003c), "Verosimilitud", voz en Diccionario de retórica y poética, 8a ed. (4a reimpr.), México: Porrúa, pp. 491-494. 
Bourdieu, P. (1997), Las reglas del arte, Barcelona: Anagrama. (1999), "Efectos de lugar", en Pierre Bourdieu (dir.), La miseria del mundo, Buenos Aires: Fondo de Cultura Económica (FCE), pp. 119-124.

(2005), La dominación masculina, 4a ed., Barcelona: Anagrama.

Cedillo, A. (2008), México: Genocidio y delitos de lesa humanidad. D ocumentos básicos 1968-2008. VIII, El fuego y el silencio. Historia de las FPL, México: Comité Pro Libertades Democráticas, A.c. ${ }^{9}$

Certeau, M. de (2000), La invención de lo cotidiano. 1 Artes de hacer, 1a reimpr., México: Universidad Iberoamericana (UIA)/Instituto Tecnológico de Estudios Superiores de Occidente (ITESO).

CROS, E. (1986), "Introducción a la sociocrítica. Conferencias 1 y 2", en Káñina. Revista de Artes y Letras de la Universidad de Costa Rica, vol. X, núm. 1, enero-junio, San José, Costa Rica: Facultad de Letras, Universidad de Costa Rica, pp. 69-84.

Delgado, A. (2003), "Las confesiones de El Fish", en Proceso. Semanario de Información y Análisis, núm. 1405, 5 de octubre, México: Comunicación e Información Sociedad Anónima (CISA), pp. 22-25.

Estebanéz, D. (2006), "Ficción", voz en Diccionario de términos literarios, 5a reimpr., Madrid: Alianza, pp. 411-412.

Giménez, G. (2007), "La concepción simbólica de la cultura”, en Gilberto Giménez Montiel, Estudios sobre cultura e identidades sociales, Guadalajara: ITESO/Consejo N acional para la Cultura y las Artes (CONACULTA), pp. 25-51.

Marchese, A., Forradellas, J. (2006), "Connotación", voz en Diccionario de retórica, crítica y terminología literaria, 8a ed., Barcelona: Ariel, pp. 75-76.

\footnotetext{
${ }^{9}$ El título del libro en portada es El fuego y el silencio. Historia delasFPL, México: Comité Pro Libertades Democráticas, A.c. Sin embargo, en el contenido del texto la autora se refiere a las Fuerzas de Liberación Nacional (FLN), lo cual - a reserva de una mejor hipótesis- sugiere un error de impresión, ya que en la página legal no aparece el título como tal.
} 
Robin, R. (2001), "Para una sociopoética del imaginario social", en Françoise Perus (comp.), Historia y literatura, 2a reimpr., México: Instituto de Investigaciones Dr. José María Luis Mora, pp. 262-300.

SAID, E. (2002), Orientalismo, Madrid: Debate.

Saltalamacchia, H. (1992), Historia de vida: reflexiones a partir de una experiencia de investigación, Caguas, Puerto Rico: Centro de Investigación para la Juventud Puertorriqueña (CIJUP).

SÁncheZ-MeSA, D. (1996), "Una teoría en expansión: la poética social dialógica del círculo de Bajtin", en Antonio Sánchez Trigueros (dir.), Sociología de la literatura, Madrid: Grupo de Investigación de Teoría de la Literatura y sus Aplicaciones, Universidad de Granada/Síntesis, pp. 191-214.

Scherer, J., Monsiváls, C. (2003), Tiempo de Saber. Prensa y poder en México, México: Aguilar.

Sewell, W. Jr. (2005), "Los conceptos de cultura”, en Gilberto Giménez Montiel et. al., Teoría y análisis de la cultura, vol. I, México: CONACULTA/Instituto Coahuilense de Cultura (ICOCULT), pp. 369-396.

N OVELAS DE GUERRILLA

Aguilar Camín, H. (1991), La guerra de Galio, México: Cal y Arena. Almanza, H. (1986), Ya despunta la aurora, México: Claves Latinoamericanas.

Avilés Fabila, R. (1973), Nueva utopía (y los guerrilleros), México: El Caballito.

Camarada, E., s/f, El Guerrillero I y II, s. p. i. (versión gubernamental). Carrión, L. (1975), El infierno de todos tan temido, México: FCE.

Castañeda, S. (1980), ¿Por qué no dijiste todo?, México: Grijalbo. (1991), Los diques del tiempo (diario de la cárcel), México: Universidad Nacional Autónoma de México (UNAM). (1992), La patria celestial, México: Cal y Arena. (1996), El de ayer es él, México: El Espejo Concéntrico. 
(2001), Papel revolución, Torreón: Dirección Municipal de Cultura (DMC), Ayuntamiento de Torreón.

Curiel, F. (1981), Manuscrito hallado en un portafolio, México: Oasis. Escobar, M. (1989), Tiempo de morir, México: Diana.

GIL OLIVo, R. (1986), Dientes de perro, México: Hexágono.

Glockner, F. (1996), Veinte de cobre. Memoria de la clandestinidad, México: Joaquín Mortiz.

(2004), Cementerio de papel. Las historias de violencia y muerte se vuelven a escuchar en el viejo Palacio de Lecumberri, M éxico: Ediciones $B$.

Godínez, P. (1968), ¡Qué poca ma... dera!, s. p. i. (versión gubernamental).10

Hirales, G. (1996), La guerra de los justos, México: Cal y Arena.

Mendiola, S. (1977), Guerra y sueño, México: Colección Plan Joven. Montemayor, C. (1991), Guerra en el paraíso, México: Seix Barral. (2003), Las balas del alba, México: Joaquín Mortiz. (2007), La fuga, México: FCE.

Mora, J. M. de (1971), La fórmula, México: Grijalbo. (1973), Si tienes miedo, M éxico: Editores Asociados Mexicanos. Ramos, A. (1979), Al cielo por asalto, México: Era/Secretaría de Educación Pública (SEP).

\footnotetext{
${ }^{10} \mathrm{El}$ guer riller o I y II, tratan sobre las guerrillas de Lucio Cabañas y la Liga 23 de septiembre y son de elaboración gubernamental. Tales textos también son mencionados en una entrevista realizada a Sergio Romero Ramírez, El Fish, para la revista Proceso (Del gado, 2003). El entrevistado afirma haber sido "activista gubernamental, leal a Díaz O rdaz y al general Corona". Sobre los libros sostiene que de "la Secretaría de Gobernación salieron estos tres libros. Todos son de la misma editorial y son de la misma pluma, un hombre de paja, porque los autores no existen". Más adel ante dice: "los repartía la Dirección Federal de Seguridad [...] y los responsables eran Fernando Gutiérrez Barrios, Miguel N azar Haro y Luis de la Barreda". De la redacción hace responsable a Jorge Joseph, "alcalde de Acapulco a principio de los sesenta". Tales textos, según el entrevistado, tenían la finalidad de inventar y "pretendieron torcer la verdad de la represión gubernamental". Por otro lado, sobre ¡Qué poca ma... dera!, Scherer y Monsiváis (2008) señalan que fue publicado en 1968, por Godínez, sobreviviente del grupo de Gámiz al asalto al Cuartel Madera. Libro "que circuló sin derechos de autor, sin registro ante la ley, sin editorial, suelto como el azar" (Scherer y Monsiváis, 2008: 92).
} 
(1982), La vida no vale nada, M éxico: Martín Casillas Editores. (1985), Ahora que me acuerdo, México: Grijalbo.

Retes, I. (2000), Por supuesto, México: O céano.

SAlAZAR, R. (1982), La sangre vacía, México: Oasis.

Fecha de recepción: 12 de mayo de 2010 Fecha de aprobación: 28 de agosto de 2010 